\title{
ROLE OF DIAGNOSTIC LAPAROSCOPY IN EVALUATION OF FEMALE INFERTILITY- OUR EXPERIENCE IN A SERIES OF 80 PATIENTS
}

\author{
Rekha Sharma1, Shabnam Rizvi², Suman Gupta ${ }^{3}$
}

${ }^{1}$ Assistant Professor, Department of Obstetrics and Gynaecology, Career Institute of Medical Sciences and Hospital, Lucknow, U. P. ${ }^{2}$ Assistant Professor, Department of Obstetrics and Gynaecology, Career Institute of Medical Sciences and Hospital, Lucknow, U. P. ${ }_{3}^{3}$ Associate Professor, Department of Obstetrics and Gynaecology, Career Institute of Medical Sciences and Hospital, Lucknow, U. P.

\section{ABSTRACT}

\section{BACKGROUND}

Female infertility is a big social and medical problem; however, its diagnosis and treatment is cumbersome. Uterine, endometrial and ovarian pathologies often remain undiagnosed. Diagnostic Laparoscopy (DL) is fast emerging to fill this gap.

The aim of this study is to evaluate the role of DL in evaluation of female infertility.

\section{MATERIALS AND METHODS}

A total of 80 infertile female patients (50 primary and 30 secondary) were enrolled in the study. Demographic and clinical history was taken. All the patients underwent laparoscopy followed by D\&C. Data was analysed using Chi-square test.

\section{RESULTS}

Majority (60\%) were of secondary infertility cases aged $>30$ years as compared to only $11(22 \%)$ of primary infertility cases. Clinically $8(16 \%)$ of primary infertility and $46.7 \%$ of secondary infertility cases were asymptomatic. Endometrial biopsy was performed. In 68 cases (42 Primary, 24 secondary) revealed abnormal pathologies in only 2 (4.8\%) cases with primary infertility. However, diagnostic laparoscopy revealed tubular and ovarian abnormalities in majority of cases. Tubal and periovarian adhesions were seen in 24 (30\%) cases, hydrosalpinx (bilateral and unilateral) in 24 (30\%), ovarian abnormalities were seen in 60\% cases. Tuberculosis, endometriosis and fibromyoma were seen in $20 \%, 7.5 \%$ and $1.25 \%$ cases. Diagnostic laparoscopy thus provided useful information about tubal, ovarian and endometrial pathologies which otherwise remained undiagnosed.

\section{CONCLUSION}

Diagnostic laparoscopy showed a high efficacy in diagnosis of causes of female infertility.

\section{KEYWORDS}

Diagnostic Laparoscopy, Female Infertility, Dilatation and Curettage, Tubal Blockade, Adhesions.

HOW TO CITE THIS ARTICLE: Sharma R, Rizvi S, Gupta S. Role of diagnostic laparoscopy in evaluation of female infertility- Our experience in a series of 80 patients. J. Evolution Med. Dent. Sci. 2017;6(21):1705-1709, DOI: 10.14260/Jemds/2017/375

\section{BACKGROUND}

Between 8 and 12 percent of couples around the world have difficulty conceiving a child at some point in their lives, and in some areas that figure reaches one-third or more. In developing countries, high levels of infertility may drain limited resources from health care systems as infertile couples repeatedly seek help for often insoluble problems. Infertility is on the rise today. The prevalence of infertility is increasing owing to change in lifestyle and social norms of marriage and conception. Every eighth couple is infertile. The term 'infertility' is used when a couple fails to conceive after one year of regular sexual activity without contraception. Eighty percent of all women desiring children, conceive within 1 year of marriage and another $10 \%$ within the second year. According to the World Health Organisation, incidence of infertility is about $10 \%$ worldwide. ${ }^{1}$ Another $10-12 \%$ of all the other couples have only one child and wish to have more. ${ }^{2}$

Financial or Other, Competing Interest: None.

Submission 05-02-2017, Peer Review 01-03-2017,

Acceptance 07-03-2017, Published 13-03-2017.

Corresponding Author:

Dr. Shabnam Rizvi,

Assistant Professor

Department of Obstetrics and Gynaecology,

Career Institute of Medical Sciences and Hospital,

Lucknow, U. P.

E-mail: dr_tahir75@yahoo.com

DOI: $10.14260 /$ jemds $/ 2017 / 375$

\section{(c) $(1) \ominus$}

The incidence of infertility is gradually increasing all over the world and in India it has been reported to be in the range of 8 to $10 \% .^{3}$

For patients undergoing in vitro fertilisation, lower pregnancy rates are observed in the presence of uterine cavity anomalies 4 and correction of these anomalies has been associated with improved pregnancy rates. ${ }^{5}$ It has been shown that uterine factors play about $15-20 \%$ role in contributing to female infertility. ${ }^{6}$ Abnormal uterine findings occur in approximately $50 \%$ of infertile women. ${ }^{7}$ Because of the high prevalence of uterine abnormalities, inspection of the uterine cavity is routinely performed in the evaluation of infertile women. Therefore, endometrial cavity assessment should be included in the evaluation of infertile couples. Most endometrial pathologies implicated in infertility result in both structural and functional impairments. ${ }^{8}$ The goal of uterine cavity evaluation is either to obtain a sample of the endometrium (Hyperplasia or Neoplasia) or to identify structural abnormalities such as polyps, myomas, or uterine septums. ${ }^{9}$ It is essential that such abnormalities should be diagnosed at the earliest. Although imaging techniques such as USG, SSG and HSG can be used for this purpose; however, they have their own limitations. ${ }^{10,11}$ Although, they are being preferred owing to their non-invasive nature ${ }^{12}$ yet the diagnosis made by these techniques is often not confirmatory and needs further evaluation. 
Laparoscopy is a minimally invasive technique the popularity of which has increased over a short period of time. It was first described by Philip Bozzini in 1805 and since 1980 the application of diagnostic and operative laparoscopy has increased.13 In 1997, Glatstein et al reported that $89 \%$ of reproductive endocrinologists routinely use laparoscopy. 14

Laparoscopy provides a panoramic view of the pelvic reproductive anatomy. The ability to see and to manipulate the uterus, fallopian tubes and ovaries during a diagnostic procedure has made laparoscopy an essential part of infertility evaluation. It can identify milder degrees of distal tubal occlusive disease (Fimbrial agglutination, phimosis, pelvic or adnexal adhesions and endometriosis). Diagnostic laparoscopy, when combined with hysteroscopy, provides useful information regarding Mullerian anomalies, pelvic pathologies, and tubal function.

Considering this promising role of laparoscopy, the present study was planned with an aim to evaluate the role of laparoscopy in evaluation of female sterility.

\section{MATERIALS AND METHODS}

Eighty women with infertility aged 20 to 44 years (both primary and secondary) attending the Department of Gynaecology and Obstetrics, Career Institute of Medical Sciences and Hospital Lucknow in the year 2014-15, were included in the assessment. Patients having at least one year of cohabitational attempts to conceive were included in the assessment. Patients having known male factor infertility, any systemic disease, known endocrinal or thyroid disorder, and those with active pelvic inflammatory disease were excluded from the assessment. Specific tests for syphilis, VDRL, complete urine analysis, Mantoux test and X-ray were routinely done for all the patients.

All the patients underwent diagnostic laparoscopic evaluation. For this purpose, laparoscope was used.

\section{Procedure}

The diagnostic laparoscopy with dye test was done in patients post-menstrually between D7-D10.

\section{Procedure for Diagnostic Laparoscopy with Chromopertubation \\ The Procedure followed for Carrying out Diagnostic Laparoscopy was as follows-}

a. Preparation of the patient: The patient was briefly explained about the procedure to be carried out and was shifted to operation theatre for carrying out the procedure. Pre-anaesthetic check-up was done.

b. Anaesthesia: The procedure was carried out under general anaesthesia.

c. Inspection of pelvis: The pelvis was examined visually for any abnormal finding to be taken care of.

d. Chromopertubation (Dye penetration): After initial inspection of the pelvis, chromopertubation was done with dilute methylene blue dye which was pushed transcervically through the Leech-Wilkinson cannula.

e. Diagnostic Laparoscopy: Laparoscopic visualisation of the free spillage of the dye into the peritoneal cavity was done to confirm tubal patency and/or any pathological finding.

\section{Dilatation and Curettage (D\&C)}

Was performed during the premenstrual phase $\left(21^{\text {st }}-28^{\text {th }}\right.$ day). Uterine cavity was curetted and endometrial curetting obtained was sent for histopathological examination as well as for Kock's culture.

\section{Data Analysis}

Data thus collected was tabulated. Findings have been shown as frequencies (Number) and proportions (percentages). A comparison between primary and secondary infertility cases was made using Chi-square test. A 'p' value less than 0.05 indicated a statistically significant association.

\section{RESULTS}

Out of 80 patients enrolled in the study, 50 (62.5\%) had primary infertility and remaining $30(37.5 \%)$ had secondary infertility. Age of patients ranged from 20 to 44 years. Majority of secondary infertility cases were aged $>30$ years $(60 \%)$ as compared to only $11(22 \%)$ of primary infertility cases, thus showing a significant difference between two groups. In secondary infertility group, there were $6(20 \%)$ cases with no history of live birth but history of one abortion, $10(33.3 \%)$ with history of one live birth, 10 (33.3\%) with one live birth and one or more abortions and 4 (13.3\%) with two live births. Clinically, in primary infertility group, 8 $(16 \%)$ had no symptoms, $6(12 \%)$ reported of menstrual disorders, 7 (14\%) had pain in abdomen, 4 (8\%) had dysmenorrhoea, 9 (18\%) had secondary amenorrhoea, 10 (20\%) had primary amenorrhoea and 6 (12\%) had leucorrhoea. On the other hand, in secondary infertility group, $14(46.7 \%)$ had no symptoms, $6(20 \%)$ had menstrual disorders, $1(3.3 \%)$ had pain in lower abdomen, 3 (10\%) had secondary amenorrhoea and 4 (13.3\%) had leucorrhoea. Statistically, there was a significant difference in clinical profile of two groups ( $\mathrm{p}=0.013)$ (Table 1).

Endometrial biopsy could be performed in 68 cases, in primary infertility group, 24 (48\%) had secretory, 16 (32\%) had proliferative endometrium while 2 (4\%) cases had tubercular endometrium whereas in secondary infertility group, $18(60 \%)$ had secretory endometrium and 8 (26.7\%) had proliferative endometrium. Statistically there was no significant difference in endometrial biopsy findings of two groups ( $\mathrm{p}=0.394)$ (Table 2$)$.

On diagnostic laparoscopy on tubal evaluation, in primary infertility group, normal tubes with bilateral patency were seen in $20(40 \%)$ cases, peritubal and periovarian adhesions were seen in $16(32 \%)$ cases ( $5 \mathrm{~B} / \mathrm{L}$ patency, $8 \mathrm{~B} / \mathrm{L}$ blockade and $3 \mathrm{U} / \mathrm{L}$ blockade), unilateral hydrosalpinx in 5 (10\%) (1 $\mathrm{B} / \mathrm{L}$ patency, $3 \mathrm{~B} / \mathrm{L}$ blockade, $2 \mathrm{U} / \mathrm{L}$ blockade), bilateral hydrosalpinx in $7(14 \%)(1 \mathrm{~B} / \mathrm{L}$ patency, $4 \mathrm{~B} / \mathrm{L}$ blockade, 2 U/L blockade) and 2 (4\%) had thick, pipe like tube. On the other hand, in secondary infertility group, 8 (26.7\%) had normal tubes with bilateral patency, $8(26.7 \%)$ had peritubal and periovarian adhesions (2 $\mathrm{B} / \mathrm{L}$ patency, $5 \mathrm{~B} / \mathrm{L}$ blockade, 1 U/L blockade), 4 (13.3\%) had unilateral hydrosalpinx (1 B/L patency, $2 \mathrm{~B} / \mathrm{L}$ blockade, $1 \mathrm{U} / \mathrm{L}$ blockade), 8 (26.7\%) had bilateral hydrosalpinx (2 B/L patency, $5 \mathrm{~B} / \mathrm{L}$ blockade, $1 \mathrm{U} / \mathrm{L}$ blockade) and $2(6.7 \%)$ had thick, pipe like tube. Statistically, there was no significant difference between two groups $(\mathrm{p}=0.527)$ (Table 3a). 
Uterine evaluation in primary infertility group revealed no abnormality in $44(88 \%)$ cases, $3(6 \%)$ had bicornuate uterus, $1(2 \%)$ each had didelphys uterus, Unicornuate uterus and septate uterus respectively whereas in secondary infertility group, 27 (90\%) had no abnormality, 2 (6.7\%) had bicornuate uterus and 1 (3.3\%) had unicornuate uterus. Statistically, there was no significant difference between two groups $(\mathrm{p}=0.852$ ) (Table $3 b)$.

Ovarian evaluation of primary infertility group revealed normal findings in 20 (40\%) cases, atrophy in 2 (4\%), cysts in $5(10 \%)$, tubo-ovarian mass 7 (14\%), endometriotic deposit over ovary in $1(2 \%)$, adhesions around ovary in $13(26 \%)$ and streak like ovaries in $2(4 \%)$ cases whereas in secondary infertility group normal findings were seen in $12(40 \%)$ cases, cysts in 4 (13.3\%), tubo-ovarian mass 4 (13.3\%), and adhesions around ovary in 10 (33.3\%). Statistically, difference between two infertility types was not significant $(\mathrm{p}=0.738)$ (Table 3c).

In primary infertility group, in $33(66 \%)$ cases no other finding was seen; however, 12 (24\%) cases were diagnosed as tuberculosis, $4(8 \%)$ as endometriosis and $1(2 \%)$ as fibromyoma whereas in secondary infertility group, 24 (80\%) had no other finding but 4 (13.3\%) had tuberculosis and 2 (6.7\%) had endometriosis. Statistically, there was no significant difference between two groups $(p=0.527)$ (Table 3d).

\begin{tabular}{|c|c|c|c|c|}
\hline $\begin{array}{l}\text { Sl. } \\
\text { No. }\end{array}$ & Characteristics & $\begin{array}{c}\text { Primary } \\
\text { Infertility } \\
(\mathrm{n}=\mathbf{5 0})\end{array}$ & $\begin{array}{c}\text { Secondary } \\
\text { Infertility } \\
(n=30)\end{array}$ & \begin{tabular}{|c|} 
Statistical \\
Significance \\
('p' value)
\end{tabular} \\
\hline 1. & Age $>30$ years & $11(22.0 \%)$ & $18(60.0 \%)$ & 0.001 \\
\hline \multirow{5}{*}{2.} & Parity & & & \\
\hline & $\mathrm{P} 0+1$ & - & $6(20.0 \%)$ & \\
\hline & $\mathrm{P} 1+0$ & - & $10(33.3 \%)$ & \\
\hline & $\mathrm{P} 1+\mathrm{x}$ & - & $10(33.3 \%)$ & \\
\hline & $\mathrm{P} 2+0$ & - & $4(13.3 \%)$ & \\
\hline \multirow{8}{*}{3.} & Clinical profile & & & \\
\hline & No symptoms & $8(16.0 \%)$ & $14(46.7 \%)$ & \multirow{7}{*}{0.013} \\
\hline & $\begin{array}{l}\text { Menstrual } \\
\text { disorders }\end{array}$ & $6(12.0 \%)$ & $6(20.0 \%)$ & \\
\hline & $\begin{array}{l}\text { Pain in lower } \\
\text { abdomen }\end{array}$ & 7 (14.0\%) & $1(3.3 \%)$ & \\
\hline & Dysmenorrhoea & $4(8.0 \%)$ & $2(6.7 \%)$ & \\
\hline & $\begin{array}{c}\text { Secondary } \\
\text { amenorrhoea }\end{array}$ & $9(18.0 \%)$ & $3(10.0 \%)$ & \\
\hline & $\begin{array}{c}\text { Primary } \\
\text { amenorrhoea }\end{array}$ & $10(20.0 \%)$ & 0 & \\
\hline & Leucorrhoea & $6(12.0 \%)$ & $4(13.3 \%)$ & \\
\hline \multicolumn{5}{|c|}{$\begin{array}{c}\text { Table 1. Demographic, Obstetric and Clinical } \\
\text { Profile of Patients }\end{array}$} \\
\hline
\end{tabular}

\begin{tabular}{|c|c|c|c|}
\hline $\begin{array}{c}\text { Sl. } \\
\text { No. }\end{array}$ & Findings & $\begin{array}{c}\text { Primary } \\
\text { Infertility } \\
(\mathbf{n = 4 2 )}\end{array}$ & $\begin{array}{c}\text { Secondary } \\
\text { Infertility } \\
\text { (n=26) }\end{array}$ \\
\hline 1. & Secretory endometrium & $24(57.1 \%)$ & $18(69.2 \%)$ \\
\hline 2. & $\begin{array}{c}\text { Proliferative } \\
\text { endometrium }\end{array}$ & $16(38.1 \%)$ & $8(30.8 \%)$ \\
\hline 3. & $\begin{array}{c}\text { Tubercular } \\
\text { endometrium }\end{array}$ & $2(4.8 \%)$ & 0 \\
\hline \multicolumn{3}{|c|}{ Table 2. Endometrial Biopsy Findings (n=68) } \\
\hline
\end{tabular}

$\chi^{2}=1.86(\mathrm{df}=2) ; \mathrm{p}=0.394(\mathrm{NS})$

\begin{tabular}{|c|c|c|c|}
\hline $\begin{array}{c}\text { Sl. } \\
\text { No. }\end{array}$ & Findings & $\begin{array}{c}\text { Primary } \\
\text { Infertility } \\
(n=50)\end{array}$ & $\begin{array}{c}\text { Secondary } \\
\text { Infertility } \\
(n=30)\end{array}$ \\
\hline \multicolumn{4}{|c|}{ (a) Tubal Evaluation } \\
\hline 1. & $\begin{array}{l}\text { Normal tubes with } \\
\text { bilateral patency }\end{array}$ & $20(40 \%)$ & $8(26.7 \%)$ \\
\hline \multirow{4}{*}{2.} & $\begin{array}{c}\text { Peritubal \& Periovarian } \\
\text { Adhesions }\end{array}$ & $16(32 \%)$ & $8(26.7 \%)$ \\
\hline & Both tubes patent & $5(10 \%)$ & $2(6.7 \%)$ \\
\hline & Both tubes blocked & $8(16 \%)$ & $5(16.7 \%)$ \\
\hline & One tube blocked & $3(6 \%)$ & $1(3.3 \%)$ \\
\hline \multirow{4}{*}{3.} & Unilateral hydrosalpinx & $5(10 \%)$ & $4(13.3 \%)$ \\
\hline & Both tubes patent & $1(2 \%)$ & $1(3.3 \%)$ \\
\hline & Both tubes blocked & $3(6 \%)$ & $2(6.7 \%)$ \\
\hline & One tube blocked & $2(2 \%)$ & $1(3.3 \%)$ \\
\hline \multirow{4}{*}{4.} & Bilateral hydrosalpinx & 7 (14\%) & $8(26.7 \%)$ \\
\hline & Both tubes patent & $1(2 \%)$ & $2(6.7 \%)$ \\
\hline & Both tubes blocked & $4(8 \%)$ & $5(16.8 \%)$ \\
\hline & One tube blocked & $2(4 \%)$ & $1(3.3 \%)$ \\
\hline 5. & Thick, pipe like tube & $2(4 \%)$ & $2(6.7 \%)$ \\
\hline \multicolumn{4}{|c|}{$\chi^{2}=3.19(\mathrm{df}=4) ; \mathrm{p}=0.527(\mathrm{NS})$} \\
\hline \multicolumn{4}{|c|}{ (b) Uterine abnormalities } \\
\hline 1. & No abnormality & $44(88 \%)$ & $27(90 \%)$ \\
\hline 2. & Bicornuate uterus & $3(6 \%)$ & $2(6.7 \%)$ \\
\hline 3. & Didelphys uterus & $1(2 \%)$ & 0 \\
\hline 4. & Unicornuate uterus & $1(2 \%)$ & $1(3.3 \%)$ \\
\hline 5. & Septate uterus & $1(2 \%)$ & 0 \\
\hline \multicolumn{4}{|c|}{$\chi^{2}=1.36(\mathrm{df}=4) ; \mathrm{p}=0.852(\mathrm{NS})$} \\
\hline \multicolumn{4}{|c|}{ (c) Ovarian abnormalities } \\
\hline 1. & Normal & $20(40 \%)$ & $12(40 \%)$ \\
\hline 2. & Atrophy & $2(4 \%)$ & $0(0 \%)$ \\
\hline 3. & Cystic & $5(10 \%)$ & $4(13.3 \%)$ \\
\hline 4. & Tubo-ovarian mass & $7(14 \%)$ & $4(13.3 \%)$ \\
\hline 5. & $\begin{array}{c}\text { Endometriotic deposit } \\
\text { over ovary }\end{array}$ & $1(2 \%)$ & $0(0 \%)$ \\
\hline 6. & Adhesions around ovary & $13(26 \%)$ & $10(33.3 \%)$ \\
\hline 7. & Streak like ovaries & $2(4 \%)$ & $0(0 \%)$ \\
\hline \multicolumn{4}{|c|}{$\chi^{2}=3.54(\mathrm{df}=6) ; \mathrm{p}=0.738(\mathrm{NS})$} \\
\hline \multicolumn{4}{|c|}{ (d) Additional Findings } \\
\hline 1. & Tuberculosis & $12(24 \%)$ & $4(13.3 \%)$ \\
\hline 2. & Endometriosis & $4(8 \%)$ & $2(6.7 \%)$ \\
\hline 3. & Fibromyoma & $1(2 \%)$ & 0 \\
\hline 4. & No additional finding & $33(66 \%)$ & $24(80.0 \%)$ \\
\hline \multicolumn{4}{|c|}{$\chi^{2}=2.23(\mathrm{df}=3) ; \mathrm{p}=0.527(\mathrm{NS})$} \\
\hline
\end{tabular}

\section{DISCUSSION}

In present study, majority of women had primary infertility $(62.5 \%)$. Primary infertility is primarily the most common reason for which women seek medical help and in different clinical studies their proportion ranges from 55\% to 75\%.15-18 In fact, the problem of not having any issue at all is much pronounced than those having at least one or more living issue. In an infertility clinic, the proportion of subjects with no issue at all is naturally higher as compared to those who had at least one or more living issue.

In present study, majority of the patients $(n=51 ; 63.8 \%)$ were aged $<30$ years. This was primarily owing to a higher proportion of patients with primary infertility. Statistical evaluation also revealed this difference. In fact, 20-30 years is the most fertile period of a woman's life and it is during this 
period in which failure to conception compels medical consultation. A similar age profile of women attending infertility clinic has also been reported in different studies from India. ${ }^{19,20}$

In present study, most of the secondary infertility group patients either had only 1 live birth or had no live birth. These findings are in accordance with the NFHS-III data ${ }^{21}$ that suggests that a majority of couples nowadays have accepted the norm of two children family; however, the desire to have a second issue as a son is the driving force behind going for the treatment of secondary infertility.

Clinically, proportion of asymptomatic women was significantly higher in secondary infertility group as compared to primary infertility group $(p=0.013)$, thus indicating that rate of pathological abnormalities contributing to secondary infertility might be higher in secondary infertility group. Prevalence of pathological abnormalities is generally associated with age and as such relatively higher age of women in secondary infertility group could be responsible for this. It must also be kept in mind that in view of a large proportion of asymptomatic women, the diagnosis and management of infertility warrants an intensive work-up, thus highlighting the need of using new technological innovations for diagnosis of infertility.

In present study, endometrial biopsy could be performed in only 68 cases; however, pathological findings were revealed in only 2 out of $42(4.8 \%)$ of primary infertility patients in whom biopsy could be done. The findings of present study endorsed the fact that dilatation and curettage has only a limited role in diagnosing the cause of infertility, it is only useful when the abnormal pathology is diffuse. ${ }^{22}$

Diagnostic laparoscopy helps to carry out an exhaustive evaluation of female infertility. In present study, we carried out the tubal, uterine and ovarian evaluation apart from an overall impression for additional findings. In both the groups, tubal abnormalities were quite common and affected majority of patients. Among different tubal abnormalities, peritubal and periovarian adhesions were most common findings in both primary and secondary infertility groups affecting $32 \%$ and $26.7 \%$ patients respectively. These findings are in agreement with the observations of Naz et al (2009) ${ }^{23}$ who also reported tubal abnormalities in $23.53 \%$ of primary and $28.07 \%$ of secondary infertility cases. Contrary to this, Nayak et al. (2013) 18 in their study found adhesions and tubal pathologies to be affecting $13 \%$ of primary and $20 \%$ of secondary infertility patients. In present study, ovarian pathologies were seen in $60 \%$ of cases in both the groups; however, Nayak et al (2013) ${ }^{18}$ found ovarian pathologies in only $8 \%$ of primary and $5 \%$ of secondary infertility cases. Naz et al (2009) ${ }^{23}$ also reported ovarian pathologies in only $13 \%$ of primary and $7 \%$ of secondary infertility cases. One of the reasons for a higher prevalence of different pathologies in present study was owing to the fact that we included atrophy and cysts as abnormal pathology whereas other studies reported it separately. ${ }^{23}$

Laparoscopic evaluation also revealed additional information in 17 (34\%) of primary infertility and 6 (20\%) of secondary infertility group patients. This is an additional finding which otherwise would have remained undiagnosed through imaging techniques. Thus, the present study showed that diagnostic laparoscopy provides a panoramic view of possible pathologies responsible for infertility in females.
Further longitudinal studies with treatment of these pathologies and their follow-up for conception are recommended.

\section{CONCLUSION}

Diagnostic laparoscopy plays a useful role in evaluation of female infertility. It provides additional information about uterine, ovarian and endometrial pathologies which are often missed by other diagnostic methods. Diagnostic laparoscopy is also useful as it can be used for treatment of these pathologies by performing hysteroscopy too.

\section{REFERENCES}

[1] Reproductive Health Outlook. Infertility: overview/lessons learned. Online (1997-2005). Available: http://www.rho.org

[2] Inhorn MC. Global infertility and the globalization of new reproductive technologies: illustration from Egypt. Soc Sci Med 2003;56(9):1837-51.

[3] Cates W, Farely TM, Rowe PJ. Patterns of infertility in the developed and developing worlds. In: Patrick RJ, Vikhlyaeva EM, (eds). Diagnosis and treatment of infertility. Bern, Hans Huber Publishers 1985.

[4] Narayan R, Rajat, Goswamy K. Treatment of submucous fibroids, and outcome of assisted conception. J Am Assoc Gynecol Laparosc 1994;1(4 Pt 1):307-11.

[5] Mooney SB, Milki AA. Effect of hysteroscopy performed in the cycle preceding controlled ovarian hyperstimulation on the outcome of in vitro fertilization. Fertil Steril 2003;79(3):637-8.

[6] Nandita P, Hrishikesh P, Suchita P. Role of hysteroscopy prior to assisted reproductive techniques. J Gynaecol Endosc Surg 2009;1(1):27-30.

[7] Brown SE, Coddington CC, Schnorr J, et al. Evaluation of outpatient hysteroscopy, saline infusion hysterosonography, and hysterosalpingography in infertile women: a prospective, randomized study. Fertil Steril 2000;74(5):1029-34.

[8] Alatas C, Aksoy E, Akarsu C, et al. Evaluation of intrauterine abnormalities in infertile patients by sonohysterography. Hum Reprod 1997;12(3):487-90.

[9] Valle RF. Hysteroscopy in the evaluation of female infertility. Am J Obstet Gynecol 1980;137(4):425-31.

[10] Rastogi R. Role of imaging in female infertility [Dr. K.M. Rai Memorial Oration Award]. Indian J Radiol Imaging 2010;20(3):168-73.

[11] Panchal S, Nagori C. Imaging techniques for assessment of tubal status. J Hum Reprod Sci 2014;7(1):2-12.

[12] Jayakrishnan K, Koshy AK, Raju R. Role of laparohysteroscopy in women with normal pelvic imaging and failed ovulation stimulation with intrauterine insemination. J Hum Reprod Sci 2010;3(1):20-4.

[13] Rock JA, Jones HW. Te Linde's operative gynaecology. Vol 9. $9^{\text {th }}$ edn. Chap-16. Lippincott Williams \& Wilkins, 2003:pg 353.

[14] Glatstein IZ, Harlow BL, Hornstein MD. Practice patterns among reproductive endocrinologists: the infertility evaluation. Fertil Steril 1997;67(3):443-51. 
[15] Wilkes S, Chinn DJ, Murdoch A, et al. Epidemiology and management of infertility: a population-based study in UK primary care. Fam Pract 2009;26(4):269-74.

[16] Suttipichate J, Sroywattana C, Dejthevaporn T, et al. Transvaginal saline sonosalpingography for the assessment of tubal patency. Thai J Obs Gyn 2002;14:223-9.

[17] Templeton A, Fraser C, Thompson B. The epidemiology of infertility in Aberdeen. BMJ 1990;301(6744):148-52.

[18] Nayak PK, Mahapatra PC, Mallick J, et al. Role of diagnostic hystero-laparoscopy in the evaluation of infertility: a retrospective study of 300 patients. J Hum Reprod Sci 2013;6(1):32-4.

[19] Kanal P, Sharma S. Study of primary infertility in females by diagnostic laparoscopy. Internet Journal of Medical Update 2006;1(2):7-9.
[20] Seal SL, Ghosh D, Saha D, et al. Comparative evaluation of sonosalpingography, hysterosalpingography, and laparoscopy for determination of tubal patency. J Obstet Gynecol India 2007;57(2):158-61.

[21] Indian Institute of Population Studies. National Family Health Survey-III 2005-2006, Final Report, 2007, Mumbai.

[22] Yang T, Pandya A, Marcal L, et al. Sonohysterography: principles, technique and role in diagnosis of endometrial pathology. World J Radiol 2013;5(3):81-7.

[23] Naz T, Hassan L, Gulmeen, et al. Laparoscopic evaluation in infertility. J Coll Physicians Surg Pak 2009;19(11):704-7. 